“C 2018 IEEE. Personal use of this material is permitted. Permission from IEEE must be obtained for all other uses, in any current or future media, including reprinting/republishing this material for advertising or promotional purposes, creating new collective works, for resale or redistribution to servers or lists, or reuse of any copyrighted component of this work in other works." 


\title{
Optical-fiber sensor network deployed for temperature measurement of large diesel engine
}

\author{
Felipe Mezzadri, Frederic C. Janzen, Gabriel Martelli, John Canning, Kevin Cook and Cicero Martelli
}

\begin{abstract}
This work presents a method to measure the temperature of the fixed and mobile bearings of a crankshaft in a large diesel engine using optical fiber Bragg gratings (FBGs). The FBG sensor development and the encapsulation with stainlesssteel tube are described. The sensors were tested in a large diesel engine in full operation and the results demonstrate the efficiency of the proposed temperature measurement method in monitoring the crankshaft bearings. It is possible to anticipate fault signals with proper processing of temperature data.
\end{abstract}

Index Terms - Bearing temperature measurement, diesel engine, optical fiber for sensing.

\section{INTRODUCTION}

$\mathrm{L}$ ARGE DIESEL ENGINES are widely used in the socalled "off-highway" applications such as mining trucks, ship propulsion, pump drives, and locomotives. The term "large diesel engine" is referred to engines with a power output higher than $560 \mathrm{~kW}$ [1] as exemplified in Fig. 1.

Such large-scale and powerful engines are generally very expensive to maintain, not only because of the sheer size of the mechanical parts involved and access difficulties, but also given the complex maintenance machinery involved and the downtime expense of having key machinery offline (for example, a container ship tie-up at dock instead of a moving cargo). Consequently, large diesel engines typically work for

Manuscript received $<$ month $><$ day $>$, $<$ Year $>$; revised $<$ month $><$ day $>$, $<$ Year $>$; accepted $<$ month $><$ day $>$, $<$ Year $>$. Date of publication $<$ month $>$ $<$ day $>$, $<$ Year $>$; date of current version $<$ month $><$ day $>,<$ Year $>$. This work was supported in part by the CAPES - Coordenação de Aperfeiçoamento de Pessoal de Nível Superior, in part by the CNPq - Conselho Nacional de Desenvolvimento Científico e Tecnológico, in part by the FINEP Financiadora de Estudos e Projetos, in part by the Fundação Araucária, and in part by the SETI - Secretaria da Ciência, Tecnologia e Ensino Superior. The associate editor coordinating the review of this paper and approving it for publication was <coordinating name>. (Corresponding author: Felipe Mezzadri.)

F. Mezzadri, G. Martelli and C. Martelli, are with the Graduate Program in Electrical and Computer Engineering, Federal University of TechnologyParana, Curitiba, Paraná 80230-901, Brazil (e-mail: felipemezzadri@utfpr.edu.br; fcjanzen@utfpr.edu.br; gmartelli@yahoo.com; cmartelli@utfpr.edu.br).

F. C. Janzen, is with the Electronic Academic Department, Federal University of Technology-Parana, Ponta Grossa, Paraná 84016-210, Brazil (email: fcjanzen@utfpr.edu.br).

J. Canning and K. Cook, are with the Interdisciplinary Photonics Laboratories (iPL), School of Chemistry, The University of Sydney, NSW 2006, Australia (e-mail: john.canning@sydney.edu.au; kevin.cook@sydney.edu.au).

Digital Object Identifier months between scheduled maintenances, during this period of time they are susceptible to major mechanical part failure, which can bring operations to a shuddering halt. Accurate and reliable monitoring of the engine's health is, therefore, of paramount importance to help in the identification of problems and efficiently schedule maintenance.

Over the years, there have been several studies dedicated to the investigation of defects that occur within diesel engines. Analysis has shown that $7 \%$ of failures in diesel engines are related to issues with the engine bearings, $24 \%$ of which are located in the crankshaft [2], [3]. These numbers are perhaps unsurprising given that the crucial role of the crankshaft is to convert the tremendous force generated by the engine into the rotation of an axle.

Various disturbances can lead to bearing failure or impair its operation. Some examples of bearing disturbances are poor lubrication, air-foamed lubricant, contaminated lubricant, faulty geometry, and overloading of the sliding partners, which appear as a result of manufacturing or assembly errors [4], [5]. These disturbances can cause wear, corrosion, material fatigue, overheating, and abnormal noises [4]. Wear on bearings, or on plane bearings more specifically, can manifest itself in several ways, which can be classified as: abrasive wear, adhesive wear, surface fatigue wear, fretting wear, cavitation wear, erosive wear, and corrosive wear [5], [6]. The damage and failure of plane bearings are classified into various categories, which are normally identified according to appearance [7].

With the objective of reducing diesel engine bearing faults various fault-detection sensors and methods have been developed. Methods, including the monitoring of the lubricant oil contamination through X-ray fluorescence, are part of the

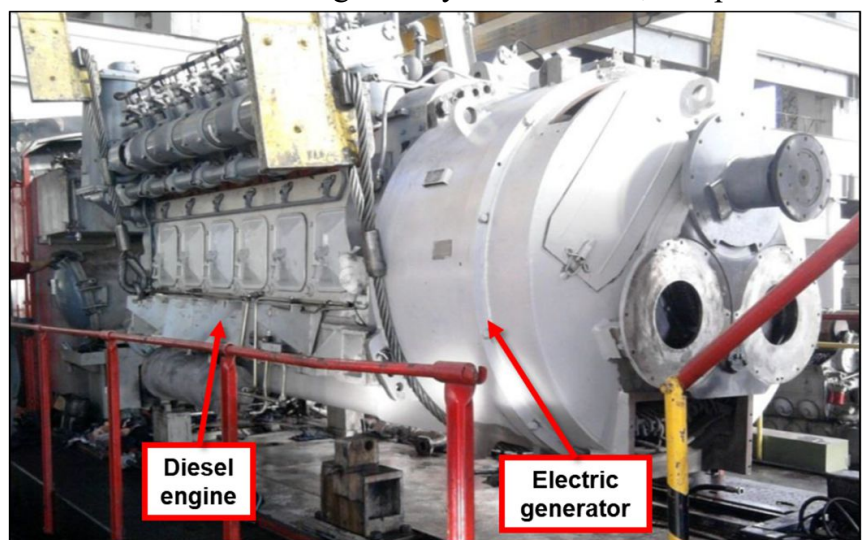

Fig. 1. Locomotive diesel engine, 12-cylinders, model C-30, manufactured by General Electric 
routine tests employed for predictive maintenance of large diesel engines. Other methods monitor the force applied to the bearings through the application of strain gauge sensors. The bearing deterioration can be monitored by measuring vibration; this can be acquired by the application of vibration or proximity sensors. Another important method used to diagnose bearing faults is through direct temperature measurement, which can indicate an excessive wear of the bearing as a result of friction [2].

To this end, our work utilizes temperature measurement of the lubricating oil to monitor crankshaft and fixed bearings, employing a multiplexed array of 24 conventional Type-I FBG sensors to form a sensing network capable of monitoring specific points inside of the engine. Conventional Type-I gratings developed for telecommunications and stabilized by heating for $10-30 \mathrm{~min}$ above $300^{\circ} \mathrm{C}$ are specified only to less than $100^{\circ} \mathrm{C}$, although certain periods of operation toward $200^{\circ} \mathrm{C}$ are possible [8]. It should be noted that the bearing temperature ranges from $72^{\circ} \mathrm{C}$ to $122^{\circ} \mathrm{C}$, depending on the rotation and load of the engine.

The FBG are positioned on top of the crankshaft bearings to measure the temperature of the lubricating oil exuded from the bearings. For the initial work, it was assumed that the oil temperature can be linearly correlated with the bearing temperature.

Among a large family of optical-fiber sensors are those based on FBGs [9], [10]. An FBG is formed by inducing a periodic modulation of the refractive index of the core of a glass, usually silicate-based optical fibers. This modulation causes the reflection of a narrow frequency band of the light propagating in the core. The reflected narrow frequency band is centered in a wavelength known as the Bragg wavelength $\lambda_{\mathcal{B}}$. The Bragg wavelength depends, mainly, on the pitch and contrast of the periodic modulation of fiber core refractive index. This makes it possible to create an array of FBGs with each FBG having its unique $\lambda_{\mathcal{B}}$.

Changes in the spatial period $\Lambda$ or the effective refractive index $n_{\text {eff }}$ of an FBG lead to a shift in $\lambda_{\mathcal{B}}$. Changes in temperature also lead to a shift in $\lambda_{\mathcal{B}}$. The combined effect of strain, sigma, and temperature, $T$, on $\lambda_{\mathcal{B}}$ may be expressed as Equation (1) [10]:

$$
\Delta \lambda_{B}=2\left(\Lambda \frac{\partial n}{\partial l}+n \frac{\partial \Lambda}{\partial l}\right) \Delta l+2\left(\Lambda \frac{\partial n}{\partial T}+n \frac{\partial \Lambda}{\partial T}\right) \Delta T
$$

where $\Lambda$ is the pitch of the FBG, $n$ is the effective refractive index of the core, $\Delta l$ is the change in FBG length, and $\Delta T$ is the change in FBG temperature.

There is a range of FBG types that can be used depending on the temperature window required. Many studies in the literature have proposed the application of FBG sensors to measure temperature in various scenarios including engine components. For example, in [11], FBG sensors are applied to measure the temperature of a turbine compressor. In [12], [13], and [14], the authors present the application of FBG sensors to measure the temperature of the cylinder head and jet engine nozzle of a diesel engine. In [15], the authors used instead regenerated FBG as an ultra-high temperature sensor to measure the higher temperatures (up to $700^{\circ} \mathrm{C}$ in this case) of the exhaust of a large diesel engine turbine. In the work presented in [16], the application of FBG temperature sensors in the temperature monitoring of heat exchangers and hydroelectric generators bearings are demonstrated.

The present work further extends the functionality of FBG sensors, focusing on Type-I FBG. The development of an optical transducer to measure the temperature of crankshaft bearings of large diesel engines is presented. First, the engine components and the type of faults that can be monitored are presented. After the development and installation of the optical transducer is described, the acquired temperature data for different operation conditions are, finally, presented and analyzed.

\section{THE DIESEL ENGINE}

Fig. 1 presents an image of a locomotive large diesel engine coupled to an electric generator produced by General Electric, which is used in the presented field tests. On the left-hand side of Fig. 1, it is possible to see the diesel engine, and on the right-hand side the electric generator, which is coupled to the crankshaft of the engine. The engine cylinders are built in a "V" layout. The engine is composed of six cylinders on each side, giving 12 cylinders in total. Each pair of cylinders consists of one mobile bearing, which connects the crankshaft to the connecting rod. Between each mobile bearing is a fixed bearing longitudinally to the shaft. Considering that the endpoint of the crankshaft is supported by a bearing, the crankshaft set is composed of 7 fixed bearings. The key function of the bearings of the crankshaft is to reduce the friction between two rotating parts, with the utilization of plain bearings proven to be the best solution [4].

Fig. 2(a) presents a schematic illustration of the crankshaft plain bearings of a large diesel engine. In relation to its shape, the plain bearings are constructed in two half-shells, with a groove to lubricate the bearing and a pressurized oil film that both lubricates and cools down the shaft and bearing interface.

Fig. 2(b) shows schematically the distribution of the fixed and mobile bearings. In diesel engines, fixed bearings were coupled to the engine block to support the crankshaft. Mobile bearings, on the other hand, are connected to the connecting rod served to rotate the crankshaft.

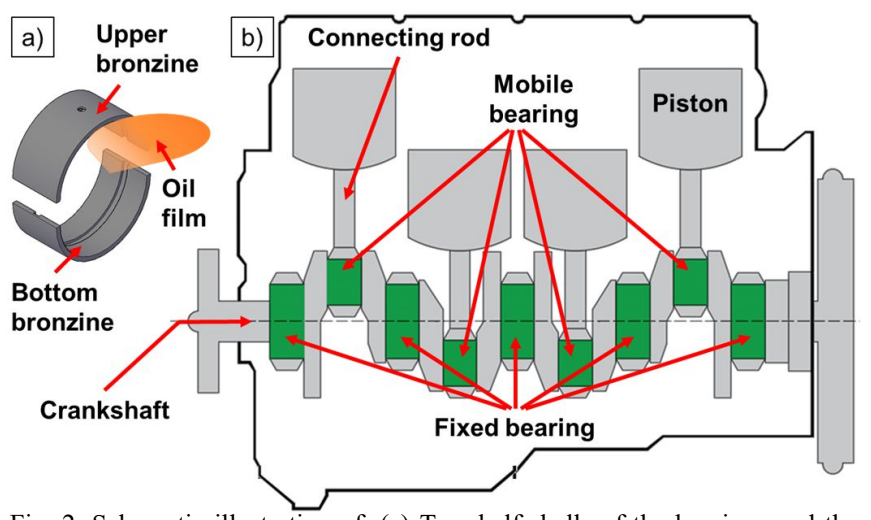

Fig. 2. Schematic illustration of: (a) Two half-shells of the bearings and the direction of the oil film; (b) Diesel engine crankshaft bearings. 


\section{A. Faults of Crankshaft Bearings of Large Diesel Engines in Locomotive Applications}

Wear and fatigue in the crankshaft bearing is a gradual process, increasing during the operation time, and can vary from day to months. In this case, the bearing shells exhibit signs of wear similar to those shown in Fig. 3(a) where the inner side of the bearing shell is observable. As a consequence of friction, the bearings heat up and consequently the lubricant oil that passes through the bearing experiences an increase in temperature. In the fault presented in Fig. 3(a), it is possible to see the carbonization of the bearing and some material deposition. This fault is considered serious and can permanently damage the crankshaft.

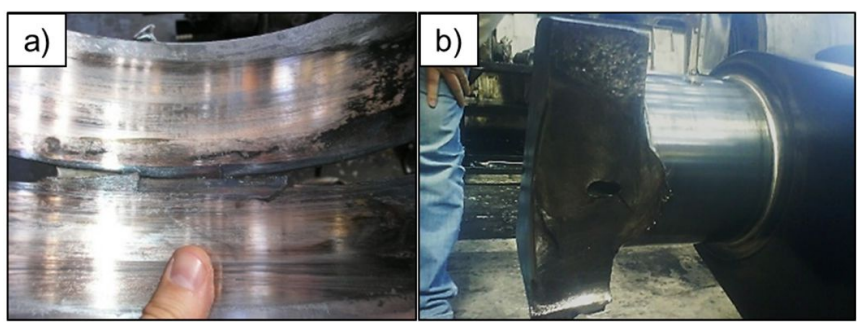

Fig. 3. (a) Inside the carbonized bronzine, showing cracks and impregnated crankshaft material due to overheating of the crankshaft bearing; (b) Crankshaft rupture due to grip on the bearing, immobilized due to lack of lubrication or excessive pressure or temperature.

Another fault that can occur is related to the connecting rod. This occurs in the junction between the bearing and the connecting rod and between the connecting rod and the bearing shells. In all these cases, a temperature rise in the oil that flows through these parts is observed.

However, the most serious fault occurs when the crankshaft is affected by an adhesive wear. The adhesive wear can damage the surface of the crankshaft journal and in more extreme cases can cause catastrophic cracking of the crankshaft as presented in Fig. 3(b).

As is the case for all types of faults, any fault or cracking is preceded by a distinct temperature increase in the region; consequently, the oil film that flows between these moving parts heats up. This temperature variation of the oil film can be used as a wear indicator for early fault monitoring. It should be noted that the boiling point of the lubricating oil ranges from $371{ }^{\circ} \mathrm{C}$ to $538^{\circ} \mathrm{C}$, depending on the pressure applied, and the engine-operating temperature does not exceed $120^{\circ} \mathrm{C}$.

\section{B. Crankshaft Bearings Temperature Measurement}

With an increase in temperature comes a corresponding increase in pressure of the lubricating oil. As a result, the oil begins to exude from the lubricant gap in both circumferential and axial directions relative to the crankshaft. By measuring the oil exuded by the bearings, it is possible to correlate the temperature, $T$, to the bearing's condition. In this way, a temperature transducer is built to measure the oil film. One of the advantages of using FBG as temperature sensors in this application is the ease with which they can be multiplexed together to perform distributed sensing of multiple bearings at various points on the crankshaft.
The transducer developed in this work is composed of 24 temperature sensors positioned over the crankshaft bearings of the engine block. Besides the high sensitivity, another advantage of the FBG temperature sensors is its small dimension, in the order of millimeters, which is important because the oil film exuded out of the bearings is very thin.

One of the challenges to be overcome, however, is the fragility of fiber-optic to shearing forces. Taking this into account, the FBG temperature sensors need to be encapsulated to protect them from the aggressive internal ambient of the large diesel engines.

\section{OPTICAL TRANSDUCER FABRICATION}

All the FBGs were fabricated in standard SMF-28 singlemode optical fiber using direct grating writing through a phase mask with an ArF laser (with central wavelength, $\lambda=193$ $\mathrm{nm}$, pulse duration, $\tau=15 \mathrm{~ns}$, pulse energy, $E_{p}=3.0 \mathrm{~mJ}$ at $4.5 \mathrm{~mJ}$, and frequency, $F=250 \mathrm{~Hz}$ at $300 \mathrm{~Hz}$ ). This resulted in the formation of stable Type-I FBG. 24 FBGs were fabricated into three sections of optical fiber. The reflected spectrum of the FBG is shown in three channels of the optical interrogator, as shown in Fig. 4. Recording was a manual process; so, there are inequalities and deformities between FBGs, being more critical the proximity of the fourth and fifth peak of Channel 2, in the order of $1555.76 \mathrm{~nm}$ and 1556.35

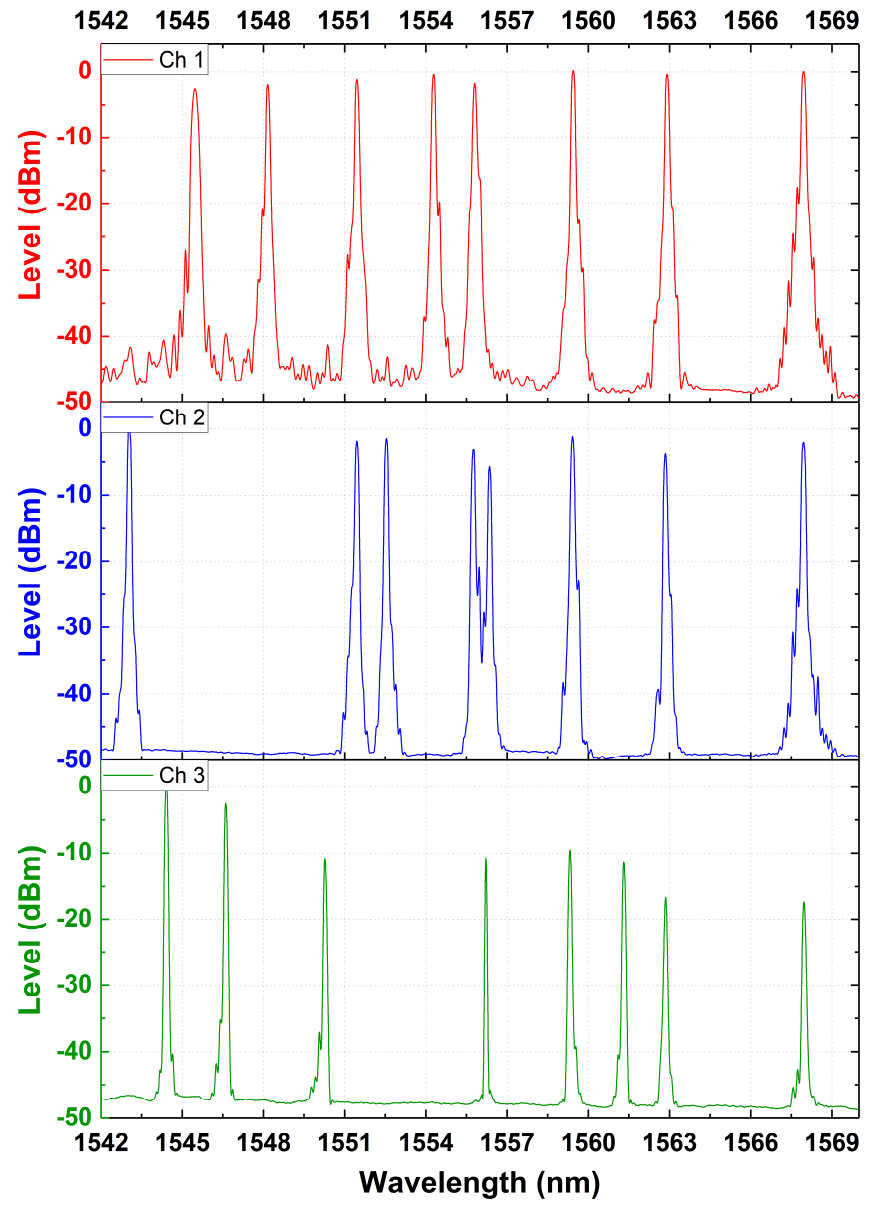

Fig. 4. Reflected spectrum of the 24 recorded FBG separated into 3 channels of the optical interrogator. 
$\mathrm{nm}$, respectively, which could overlap. However, in temperature measurement, this difference is $57.8^{\circ} \mathrm{C}$; so, there was no overlap of the peaks, as they move proportionally as the engine temperature increases. If there is such a difference, the engine will be doomed.

To protect the FBG sensors from the aggressive environment inside the engine, they were inserted inside a stainless-steel pipe of 2.6-m long, 1/8" of diameter, and 1/36" of wall thickness. Stainless steel was chosen because of its high capacity to resist corrosion, to support high temperatures, and its low thermal expansion coefficient.

The transducer is divided into three parts: a stainless-steel pipe, which is fixed to the engine block using aluminum clamps, a derivation box, separating the internal engine components of the transducer from the external parts, and optical fiber with the FBG temperature sensors. Fig. 5(b) shows an image of the transducer.

The derivation box, fixed to the wall of the engine block (Fig. 5(a)), consists of a metallic box that is used to accommodate the fiber-optic splices and optical connectors. The connection between the transducer and the monitoring system is made through an optical cable, which is resistant to harsh environments. The fitting of the stainless-steel pipe with the FBG sensors to the engine block is made by using aluminum clamps glued to the engine block using a high temperature silicone glue, as shown in Fig. 5(c).

It is important to avoid that the vibrations caused during the engine operation or by the locomotive movement do not interfere in the temperature value because of strains applied to the sensors. The multiplexed FBG sensors are inserted into the stainless-steel pipe and fixed only at one end to avoid any strain on the fiber. Having the sensor array unstrained is

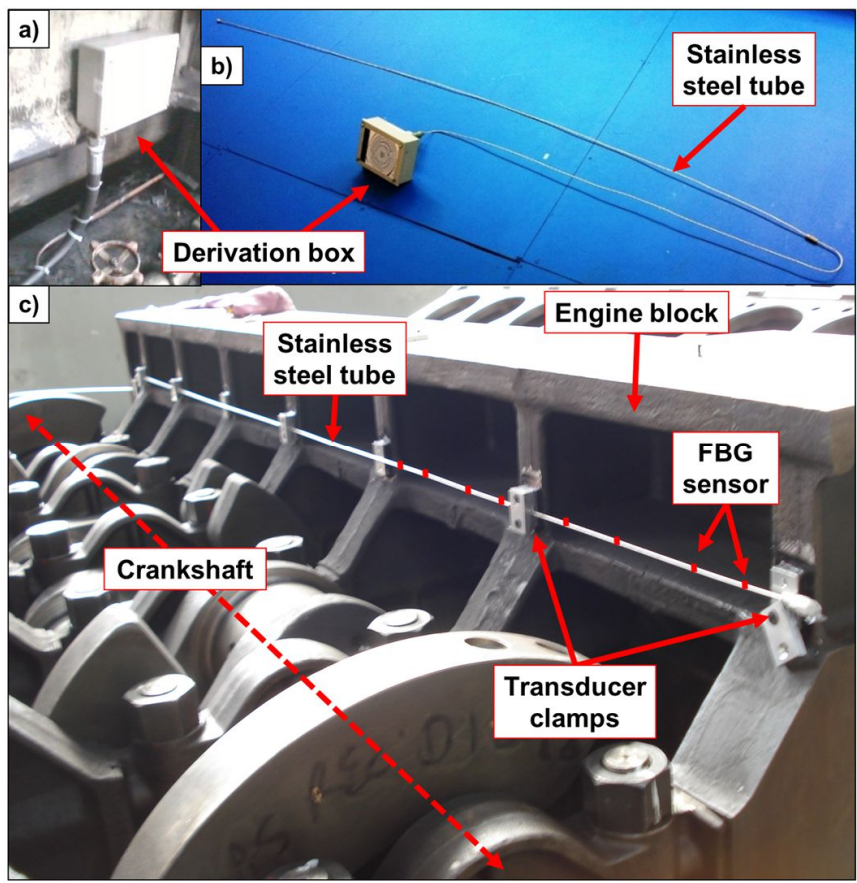

Fig. 5. (a) Derivation box installed in the engine block; (b) Complete optical temperature transducer with the FBG sensor and derivation box; (c) Optical temperature transducer positioned inside the engine (the engine is upside down and without crankcase). essential to remove the strain contribution to $\Delta \lambda_{B}$ (the first component in equation (1)), leaving $\Delta \lambda_{B}$ corresponding to changes in temperature only.

All the 24 FBGs were calibrated for temperature using a thermal bath (LAUDA ${ }^{\circledR}$ ECO RE415G). A 3-m-long thermal isolated copper pipe was coupled to the FBG. Through the pipe flows silicon oil, the temperature of which is controlled by the thermal bath. The measured difference in temperature for the silicon oil between the input and output of the copper pipe was $0.04^{\circ} \mathrm{C}$. After the developed transducer with the 24 encapsulated FBGs was inserted into the copper pipe, the temperature of the thermal bath was programmed to increase in steps of $10^{\circ} \mathrm{C}$ up to $100^{\circ} \mathrm{C}$. After stabilizing at each step, the peak wavelength of each FBG was acquired.

The calibration coefficients were minimum of $9.7 \mathrm{pm} /{ }^{\circ} \mathrm{C}$ and maximum $10.7 \mathrm{pm} /{ }^{\circ} \mathrm{C}$ and a standard deviation of $5 \%$ was estimated. The calculated calibration coefficient for all FBGs was $10.2 \mathrm{pm} /{ }^{\circ} \mathrm{C}$. It is known that $5 \%$ is $0.51 \mathrm{pm}$ and $0.05^{\circ} \mathrm{C}$ being very small values that do not interfere in the system, since the optical interrogator has a Wavelength Delta of $5 \mathrm{pm}$.

The temperature-monitoring system reads the FBG signal, converts the signal into temperature, and stores the data. The interrogator system (SM125 from Micron Optics ${ }^{\circledR}$ ). The power source for the system uses a DC/DC converter, converting 72 VDC of the locomotive system into 12 VDC. An electronic circuit is also included to log some other important parameters such as the locomotive operation status and generates an alarm in the event of fault detection.

The industrial computer executes the software known as MOI Enlight, developed by Micron Optics ${ }^{\circledR}$ for the optical interrogation system. The software is responsible for acquiring the FBG signal, detecting the FBG peaks, converting peak wavelength to temperature, displaying these temperatures in a graphic form, and finally saving the temperature data to file. Proprietary software is also developed to interpret the temperature data and generate warnings and alarms. The scan time was $1 \mathrm{~s}$.

\section{RESUlTS}

With the objective of testing the proposed system, experimental tests during the operation of a locomotive large diesel engine are performed. The measurements are made during a maintenance test of the engine, which involves stressing the engine in all its 8 rotation speed points, as shown in Table I. The maintenance test can also include the turning $\mathrm{ON} / \mathrm{OFF}$ of the electric generator, which in this case is connected to a resistive load.

TABLE I

RotATION SPEEd POINTS OF THE GE C30 DIESEL ENGINE

\begin{tabular}{cc}
\hline \hline Rotation Speed Point & Rotation (RPM) \\
\hline $1^{\text {st }}$ & $445-453$ \\
$2^{\text {nd }}$ & $521-549$ \\
$3^{\text {rd }}$ & $704-712$ \\
$4^{\text {th }}$ & $758-788$ \\
$5^{\text {th }}$ & $876-884$ \\
$6^{\text {th }}$ & $876-884$ \\
$7^{\text {th }}$ & $962-980$ \\
$8^{\text {th }}$ & $1049-1057$ \\
\hline \hline
\end{tabular}


Initially, the engine with the sensors was turned on for $5 \mathrm{~h}$ under normal operating conditions, ranging from the $1^{\text {st }}$ to $8^{\text {th }}$ rotation speed point. With the rotation of the crankshaft, the oil films of the bearings reached the 24 sensors and the temperature variation values were recorded and are shown in Fig. 6.

Fig. 6 has two graphs: The upper graph shows the actual temperature data of the 24 sensors for $5 \mathrm{~h}$ and the bottom graph shows the difference of each sensor of the instantaneous average of the 24 sensors. In addition, the graphs in Fig. 6 are divided into five different engine operation moments, as follows:

I) Increasing from the $1^{\text {st }}$ to $7^{\text {th }}$ rotation speed point with load;

II) Decreasing to the $5^{\text {th }}$ rotation speed point with load;

III) Increasing from the $6^{\text {th }}$ to $7^{\text {th }}$ rotation speed point with load;

IV) $8^{\text {th }}$ rotation speed point with load;

V) Decreasing to the $7^{\text {th }}$ to $4^{\text {th }}$ rotation speed point with load.

In the upper graph of Fig. 6, it can be seen that all sensors have proportional response to the operation of the engine with higher temperature values being more prominent when the speed of rotation is high. On the graph showing the average

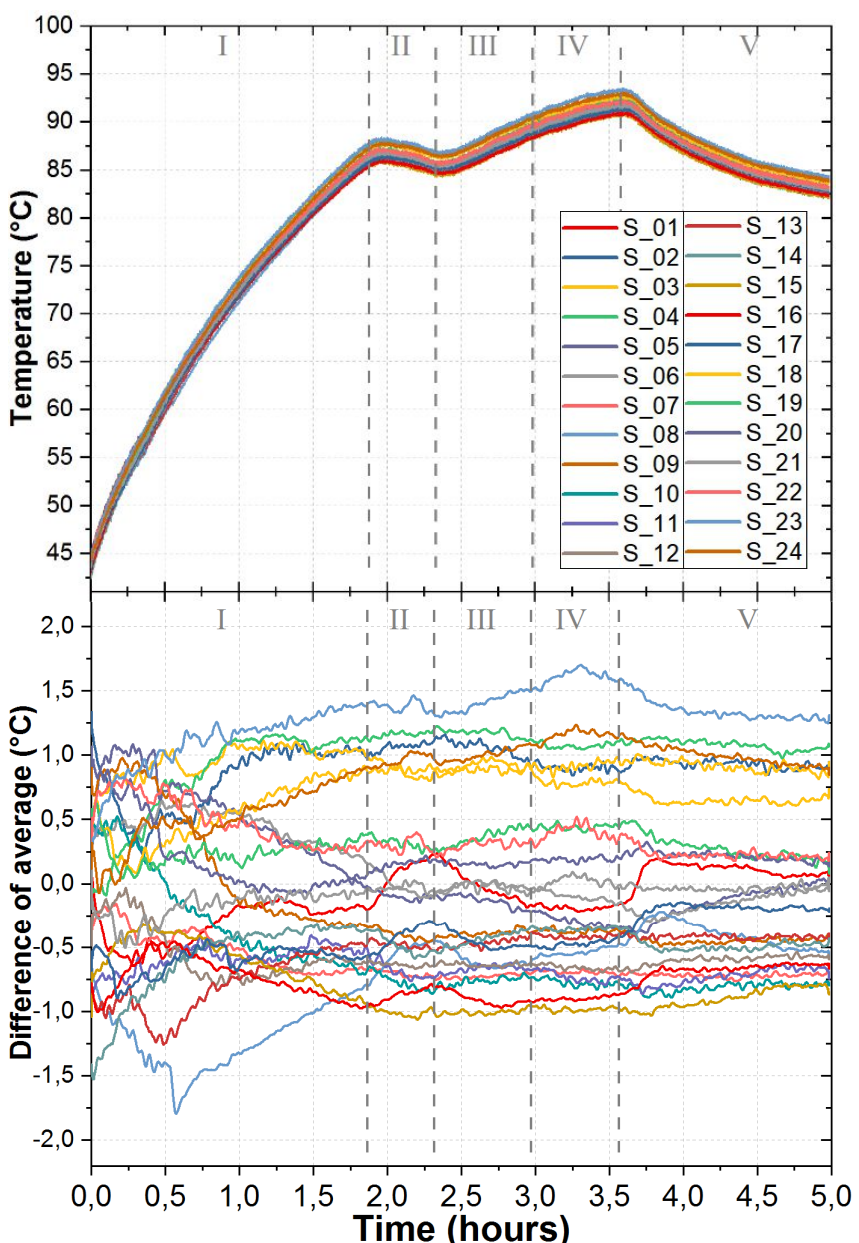

Fig. 6. Temperature of the bearings under normal operating conditions measured by the $24 \mathrm{FBGs}$ for $5 \mathrm{~h}$ and comparison with the difference of average temperature showing that it does not exceed $\pm 2{ }^{\circ} \mathrm{C}$. temperature difference (bottom graph of Fig. 6), it is possible to observe that 24 sensors work uniformly respecting a maximum difference $+-2^{\circ} \mathrm{C}$ at all moments. In this way, it was possible to identify the normal operating temperature of the diesel engine. The engine was shut down after $5 \mathrm{~h}$ of operation and the temperature measurement of the bearings was also performed quickly with an infrared pyrometer. The pyrometer temperature measurement data are shown in Table II. Then, there are two difficulties, the FBG only works when the engine is turned on and the pyrometer only works when the engine is off.

TABLE II

ENGINE TEMPERATURE Under NORMAL CONDITIONS MEASURED WiTH PYROMETER AFTER ENGINE SHUTDOWN

\begin{tabular}{cc}
\hline \hline Bearing ID & Temperature $\left({ }^{\circ} \mathrm{C}\right)$ \\
\hline $7^{\text {th }}$ Fixed bearing & 77.8 \\
$6^{\text {th }}$ Mobile bearing & 78.1 \\
$6^{\text {th }}$ Fixed bearing & 77.1 \\
$5^{\text {th }}$ Mobile bearing & 78.5 \\
$5^{\text {th }}$ Fixed bearing & 79.4 \\
$4^{\text {th }}$ Mobile bearing & 79.5 \\
$4^{\text {th }}$ Fixed bearing & 80.1 \\
$3^{\text {rd }}$ Mobile bearing & 80.2 \\
$3^{\text {rd }}$ Fixed bearing & 79.7 \\
$2^{\text {nd }}$ Mobile bearing & 80.1 \\
$2^{\text {nd }}$ Fixed bearing & 79.2 \\
$1^{\text {st }}$ Mobile bearing & 77.8 \\
$1^{\text {st }}$ Fixed bearing & 78.4 \\
\hline
\end{tabular}

It should be noted that the measurement with the pyrometer is imprecise, as it was done after the engine was shut down and the pyrometer was still pointing to the uneven surface of each bearing and the atmosphere had smoke and oil spray. Although inaccurate, there is no overheating in the bearings and a temperature measured as FBG is consistent with the pyrometer.

In another test performed during engine maintenance, the connecting rod of the $5^{\text {th }}$ bearing was intentionally tightened slightly more than usual, with the objective to simulate a fault. The connecting rod of the $2^{\text {nd }}$ bearing was slightly loosened to simulate an incorrect mounting of the bearing. A layout of the temperature sensors in relation to the bearings is presented in Table III.

TABLE III

IDENTIFICATION AND Positioning OF THE SENSORS AND DiESEL ENGINE MODIFICATION INDICATION

\begin{tabular}{ccc}
\hline \hline Sensor ID & Bearing ID & Note \\
\hline S_01 & $7^{\text {th }}$ Fixed bearing & Without changes \\
S_02 and S_03 & $6^{\text {th }}$ Mobile bearing & Without changes \\
S_04 and S_05 & $6^{\text {th }}$ Fixed bearing & Without changes \\
S_06 and S_07 & $5^{\text {th }}$ Mobile bearing & Tightened \\
S_08 and S_09 & $5^{\text {th }}$ Fixed bearing & Without changes \\
S_10 and S_11 & $4^{\text {th }}$ Mobile bearing & Without changes \\
S_12 and S_13 & $4^{\text {th }}$ Fixed bearing & Without changes \\
S_14 and S_15 & $3^{\text {rd }}$ Mobile bearing & Without changes \\
S_16 and S_17 & $3^{\text {rd }}$ Fixed bearing & Without changes \\
S_18 and S_19 & $2^{\text {nd }}$ Mobile bearing & Loosened \\
S_20 and S_21 & $2^{\text {nd }}$ Fixed bearing & Without changes \\
S_22 and S_23 & $1^{\text {st }}$ Mobile bearing & Without changes \\
S_24 & $1^{\text {st }}$ Fixed bearing & Without changes \\
\hline \hline
\end{tabular}

In the test presented in Fig. 8, the temperatures of the bearings were measured for six different engine operation moments:

I) Region where the engine is turned off (the data which corresponds to times where the engine is off can be disregarded as there is no oil moving over the sensors); 


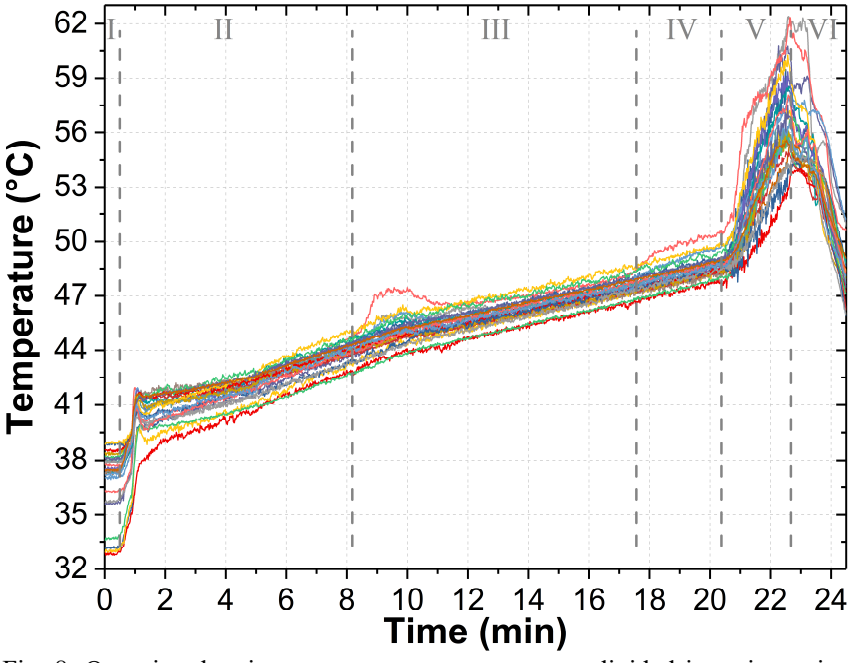

Fig. 8. Overview bearings temperature measurement divided into six engine operating moments (the color legend is the same as in Fig. 6).

II) Engine is turned on. After $5 \mathrm{~min}$, the speed point is increased to the $2^{\text {nd }}$ rotation speed point without load;

III) $3^{\text {rd }}$ rotation speed point without load;

IV) Decreasing to the $2^{\text {nd }}$ rotation speed point and introduction of the resistive load to the generator circuit;

V) Increasing from the $3^{\text {rd }}$ to $7^{\text {th }}$ rotation speed point with load;

VI) Engine is shut down.

Region II in Fig. 8 shows the engine operation running slowly, being thus not stressing significantly the mechanic components, so that the temperature difference between each sensor stayed by $3^{\circ} \mathrm{C}$.

It is possible to see in the beginning of the region III in Fig. 8, after 9 min of operation, sensors S_06 and S_07, in gray and red colors, respectively, show a distinct peak in temperature out of line with the other sensor trends. This temperature increase is a direct result of the over-tightened $5^{\text {th }}$ mobile bearing and its increased friction. This fault can take a while to appear in normal operation.

In region $\mathrm{IV}$, beyond the temperature increase of the $5^{\text {th }}$ mobile bearing, it is also observed that the temperature of the $2^{\text {nd }}$ bearing starts to increase by the value of $S_{-} 18$ shown with yellow line. This temperature increase is smaller than that presented by the $5^{\text {th }}$ bearing as it forms as a result of loosening (under-tightening) of the bearing and less friction is generated than the overtightened case. In this way, the $2^{\text {nd }}$ moving bearing is more lubricated.

A close-up of regions IV, V, and VI in Fig. 8 for the $2^{\text {nd }}$ and $5^{\text {th }}$ mobile bearings is presented in Fig. 7. By analyzing Fig. 7, it is possible to observe that in the $3^{\text {rd }}$ rotation speed point, the temperature of the $5^{\text {th }}$ bearing increases significantly, and the $2^{\text {nd }}$ bearing exhibits a slight increase in temperature. As the engine speeds up, the $2^{\text {nd }}$ bearing becomes more lubricated and its temperature normalizes in relation to the other bearings as may be expected. Finally, in region $\mathrm{V}$ (where the rotation speed point was increased from the $3^{\text {rd }}$ to the $7^{\text {th }}$ rotation speed point with a load on the generator), Fig. 7 shows that the temperature peaks at approximately $62,5^{\circ} \mathrm{C}$, and that the

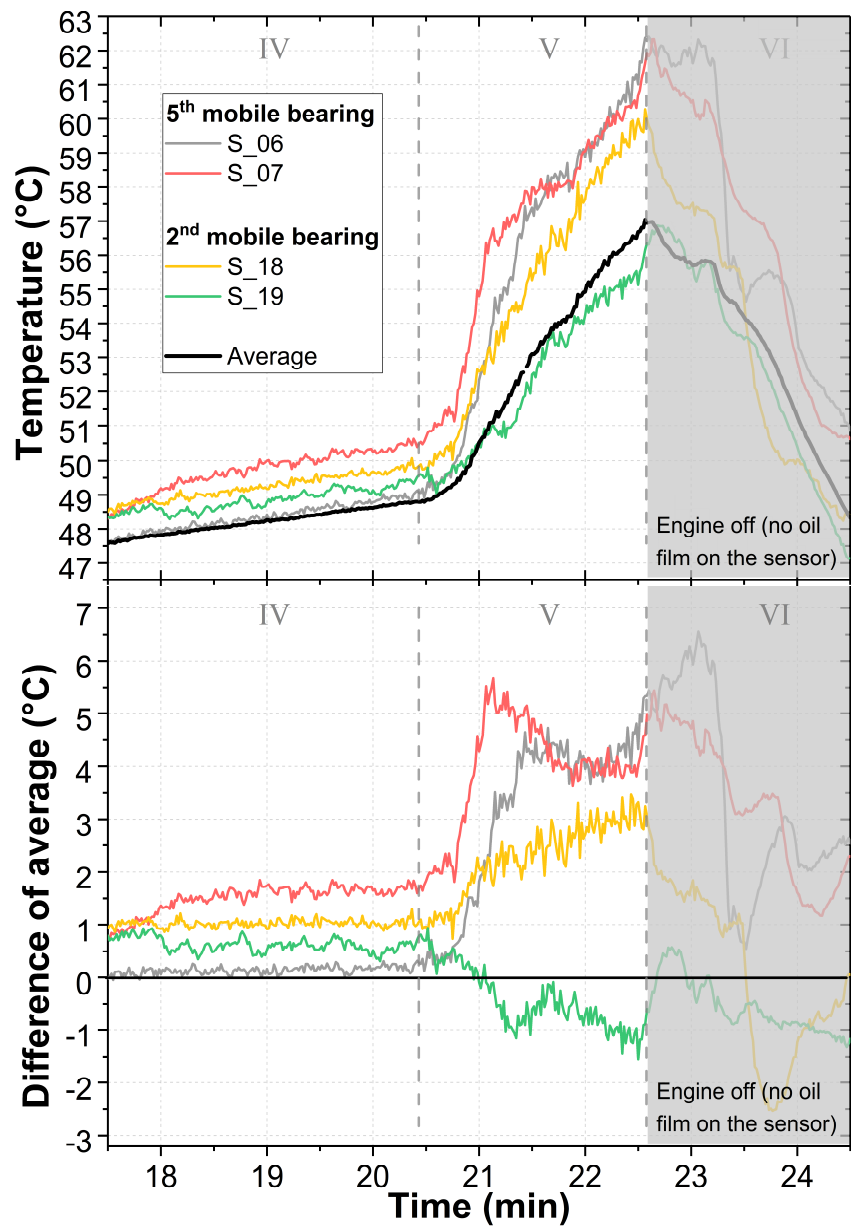

Fig. 7. Close-up of regions IV, V, and VI of Fig. 8, showing the overtemperature measured by the sensors of the 2 nd and 5 th mobile bearings and the comparison with the difference of average temperature showing that overheated and underheated.

difference of S_07 in the mean temperature reached $5.6^{\circ} \mathrm{C}$, which is post examination of the crankshaft, indicating damage to the plain bearings.

Again, the temperature measurement with the infrared pyrometer was performed after the engine shutdown. The data are presented in Table IV, where it can be seen that $2^{\text {nd }}$ and $5^{\text {th }}$ bearings were overheated.

To improve the temperature profile representation of the crankshaft, a thermal map was plotted to better understand the temperature distribution along the transducer. This map is

TABLE IV

Modified Engine Temperature MeAsured With Pyrometer After ENGINE SHUTDOWN

\begin{tabular}{cc}
\hline \hline Bearing ID & Temperature $\left({ }^{\circ} \mathrm{C}\right)$ \\
\hline $7^{\text {th }}$ Fixed bearing & 60.6 \\
$6^{\text {th }}$ Mobile bearing & 69.5 \\
$6^{\text {th }}$ Fixed bearing & 50.9 \\
$5^{\text {th }}$ Mobile bearing & 75.2 \\
$5^{\text {th }}$ Fixed bearing & 65.2 \\
$4^{\text {th }}$ Mobile bearing & 70.0 \\
$4^{\text {th }}$ Fixed bearing & 57.9 \\
$3^{\text {rd }}$ Mobile bearing & 66.1 \\
$3^{\text {rd }}$ Fixed bearing & 59.3 \\
$2^{\text {nd }}$ Mobile bearing & 72.0 \\
$2^{\text {nd }}$ Fixed bearing & 66.8 \\
$1^{\text {st }}$ Mobile bearing & 67.3 \\
$1^{\text {st }}$ Fixed bearing & 67.7 \\
\hline \hline
\end{tabular}




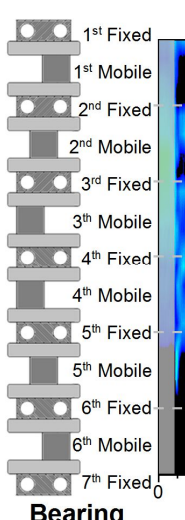

Bearing

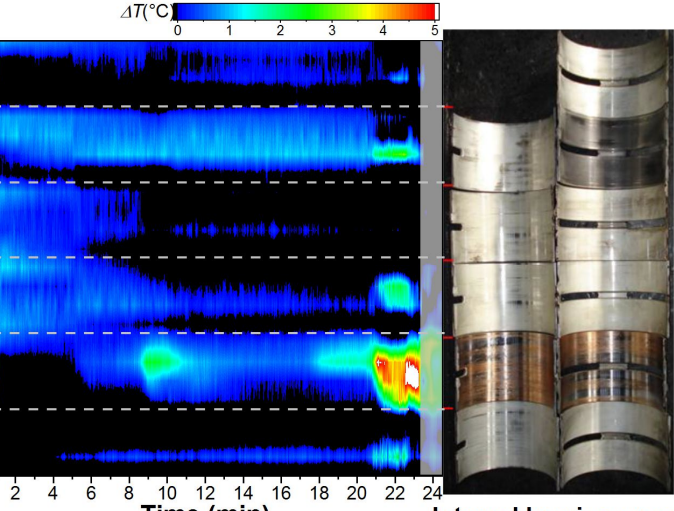

Time (min)

Internal bearing wear

Fig. 9. Average difference thermal map of the crankshaft bearings evidencing the wear caused to plain bearings during the tests.

presented in Fig. 9, where the X-axis corresponds to the time in minutes and the $\mathrm{Y}$-axis to the bearing position. Fig. 9 illustrates more clearly how the $2^{\text {nd }}$ and $5^{\text {th }}$ become overheated.

It is possible to see in Fig. 9 that the $2^{\text {nd }}$ and $5^{\text {th }}$ bearings, in the regions which correspond to regions II, III, and IV from Fig. 8, are working significantly hotter than other points. The $3^{\text {rd }}$ bearing operates at a cooler temperature than the others, which indicates more lubrication.

By analyzing the region in Fig. 9 corresponding to the region $\mathrm{V}$ from Fig. 7 , it is possible to observe that the $2^{\text {nd }}$ and $5^{\text {th }}$ bearings operate at approximately $5.6^{\circ} \mathrm{C}$ higher than the other bearings. Fig. 9 also clearly shows the heating of the $2^{\text {nd }}$ mobile bearing (intentionally loosened) to $\sim 4^{\circ} \mathrm{C}$ above the average bearing temperature at that point in the test. To analyze any damage caused to the plain bearings due to the performed tests, the plain bearings were subsequently removed from the engine and subjected to a visual inspection.

To analyze the damages, the images of the crankshaft mobile bearings are presented on the right side of Fig. 9 attached to the thermal map. These images clearly show visible damage and discoloration to the $2^{\text {nd }}$ and $5^{\text {th }}$ mobile bearings as expected.

All the mobile bearings also show wear, but in a lower proportion when compared with the $2^{\text {nd }}$ and $5^{\text {th }}$ mobile bearings.

\section{CONCLUSIONS}

In this work, the development and validation of a new method to measure the temperature of the crankshaft bearings of large diesel engines is presented using an optical-fiber sensor network of FBG. By intentionally loosening and tightening specific mobile bearings prior to a maintenance test, it was possible to clearly detect the temperature increases caused by such faults.

The main difference between the two faults is the amount of lubrication fluid that flows through the bearings.
By analyzing the thermal map presented in Fig. 9, it is possible to see the thermal distribution along the crankshaft. By visually analyzing the plain bearings from the crankshaft, it clearly shows the relation between the measured temperature and the damages caused to the bearings.

It is possible to conclude that the proposed sensor network shows excellent promise as an effective approach to monitor the health of diesel engines, helping detect emerging faults and schedule maintenance before catastrophic damage has a chance to occur. Such sensing technology applied to large diesel engines has far-reaching application areas from rail locomotives and container ships to power stations and mines.

\section{REFERENCES}

[1] Chatterjee, D., \& Rusch, K. (2014). SCR Technology for Off-highway (Large Diesel Engine) Applications. In Urea-SCR Technology for deNOx After Treatment of Diesel Exhausts (pp. 33-61). Springer New York.

[2] Collacott, R. A. (1977). Failure types, investigation and occurrences. In Mechanical Fault Diagnosis and condition monitoring (pp. 1-15). Springer Netherlands.

[3] VERSICHERUNGS-AG, Allianz. Handbook of loss prevention. Springer Berlin Heidelberg, 1978.

[4] Mollenhauer, K., \& Tschöke, H. (Eds.). (2010). Handbook of diesel engines. Springer Science \& Business Media.

[5] Vencl, A., \& Rac, A. (2014). Diesel engine crankshaft journal bearings failures: Case study. Engineering Failure Analysis, 44, 217-228.

[6] Rac, A. (1991). Basics of tribology. Faculty of Mechanical Engineering, University of Belgrade, Belgrade, 7-23.

[7] Affonso, L. O. A. (2013). Machinery Failure Analysis Handbook: sustain your operations and maximize uptime. Elsevier.

[8] Åslund, M., Canning, J., Stevenson, M., \& Cook, K., "Thermal stabilization of Type I fiber Bragg gratings for operation up to $600^{\circ} \mathrm{C}$," Opt. Lett. 35, 586-588 (2010).

[9] Kashyap, R. (1999). Fiber bragg gratings. Academic press.

[10] Othonos, A. (1997). Fiber bragg gratings. Review of scientific instruments, 68(12), 4309-4341.

[11] Polz, L., Zeisberger, A., Bartelt, H., \& Roths, J. (2016). Total Temperature Measurement of Fast Air Streams With Fiber-Optic Bragg Grating Sensors. IEEE Sensors Journal, 16(17), 6596-6603.

[12] Zhang, H., Jiang, Q., Wang, B. Y., \& Wang, J. J. (2016). Monitoring diesel engine parameters based on FBG probe. Optoelectronics Letters, 12(5), 384-388.

[13] Fan, X., Jiang, Q., Li, G., Hu, Y., Wu, Q., \& Wang, Y. (2014). Engine Cylinder Head Temperature Measurement Based on Optical Fiber Probe. Journal of Testing and Evaluation, 43(4), 758-764.

[14] Yu, L., Wang, D. Y., Wang, Y., Collins, C. M., Schneck, W. C., Bailey, J. M., ... \& Wang, A. (2013, May). Engine test for wavelengthmultiplexed fiber Bragg grating temperature sensor. In SPIE Defense, Security, and Sensing (pp. 872209-872209). International Society for Optics and Photonics.

[15] Mezzadri, F., Janzen, F. C., Canning, J., Cook, K. \& Martelli, C. "Monitoramento de temperatura em turbina de motor diesel de locomotiva com sensor a fibra óptica”. In: MOMAG, 2012, João Pessoa - PB. $15^{\circ}$ SBMO - Simpósio Brasileiro de Micro-ondas e Optoeletrônica $\& 10^{\circ} \mathrm{CBMag}$ - Congresso Brasileiro de Eletromagnetismo, 2012.

[16] Dreyer, U. J., Silva, E. V., Di Renzoa, A. B., Mezzadri, F., Kalinowski, H. J., de Oliveiraa Oliveira, V., ... \& Silva, J. C. C. (2015). Fiber Optic Temperature Sensing in Heat Exchangers and Bearings for Hydro Generators. Journal of Microwaves, Optoelectronics and Electromagnetic Applications (JMOe), 14, 35-44. 